\title{
Heteronormativity in schools is associated with unhealthy weight-control behaviors in Lesbian, Gay, and Bisexual youth: A multilevel analysis.
}

Carolina da Franca Bandeira Ferreira Santos ( $\sim$ carolina.franca@upe.br)

Universidade de Pernambuco https://orcid.org/0000-0002-7365-2806

\section{Fabiana Godoy}

Universidade de Pernambuco

\section{Valdenice Menezes}

Universidade de Pernambuco

\section{Viviane Colares}

Universidade de Pernambuco

\section{Patrícia Zarzar}

Universidade Federal de Minas Gerais

\section{Raquel Ferreira}

Universidade Federal de Minas Gerais

Ichiro Kawachi

Harvard University T H Chan School of Public Health

\section{Research article}

Keywords: Sexual and Gender Minorities, Schools, Feeding and Eating Disorders, Adolescent, Multilevel Analysis.

Posted Date: August 25th, 2020

DOI: https://doi.org/10.21203/rs.3.rs-60027/v1

License: (a) (1) This work is licensed under a Creative Commons Attribution 4.0 International License. Read Full License 


\section{Abstract}

Background Previous studies found that a school climate of more heteronormativity is associated with adverse effects on the mental health of LGB students. Accordingly, our aim was to assess the association between low LGB visibility in schools and unhealthy weight-control behaviors among LGB youth.

Methods Cross-sectional, multilevel study based in public high schools in the city of Olinda, Northeast Brazil. A multilevel logistic regression was performed, including 2,500 adolescents enrolled in 27 schools. The contextual variable was the prevalence of LGB youth in each school (as a proxy for heteronormativity in schools) while the outcome was unhealthy weight-control behaviors (fasting, purging, and taking diet pills). We controlled for socioeconomic characteristics (age, gender, receiving a family allowance), obesity, and self-reported happiness.

Results Low LGB visibility in schools was associated with higher odds of engaging in unhealthy weightcontrol behaviors (OR: $1.5,95 \% \mathrm{Cl}: 1.0,2.2$ ) among all youth, regardless of sexual orientation. Among LGB youth, there was some suggestion that the association between LGB visibility and unhealthy weight control behaviors was mediated by experiences of victimization and self-perceptions of unhappiness.

Conclusion A school environment of low LGB visibility was associated with unhealthy weight-control behaviors in youth.

\section{Background}

Schools need to be a safe place to guarantee the healthy development of their students. Sexual and gender minority youth are more likely to report negative school environment perceptions and experiences. $[1,2]$ For example, schools with more heteronormative norms have been found to be associated with adverse effects on depressed mood for all boys, i.e., regardless of low or high gender typicality. [3] Gower et al. [4] found that schools with more supportive LGBT climates had students reporting lower odds of victimization, regardless of their sexual orientation. Poteat et al. [5] showed that victimization had a direct effect on suicide behavior and school belonging, and an indirect effect on educational outcomes (reported grades, truancy, and graduation) for all students regardless of sexuality. A Brazilian study showed that students who reported experiencing homophobic discrimination evaluated their school experience less positively.[6] However, according to Johns et al., [7] there is still a need for school-based research among sexual and gender minority youth.

Outwardly, Brazil projects an image of a liberal-progressive country with regard to issues of sexuality, probably because of its famous Carnival and the visibility of gay activists.[8] Contrary to that popular image, however, Brazil is one of the countries with the highest toll of deaths attributed to homophobic violence,[9] and the numbers in Brazil's Northeast are among the worst.[10] Despite advances in LGBT rights during the last few years,[11] it is important to consider that virtually all the progress in Brazilian LGBT legislation was based on judicial fiat instead of legislation proposed at the federal level. [8] In addition, in the wake of the last presidential election, the Brazilian population is becoming more 
intolerant. The Inter-American Commission on Human Rights has declared that the life of a gay member of the Brazilian Congress was "at grave risk" and that the state was not doing enough to protect them. Fear has driven some politicians to voluntarily drive themselves into exile.[12] The Brazilian president and his staff have repeatedly made overt homophobic statements in public.[13, 14] This homophobic tendency is already reflected in policies such as the removal of sex education from the Brazilian Education Plan[15] and a bill proposed by a senator for criminalizing homosexuality in schools.[16]

Brazilian adolescents report widespread negative and even violent reactions from their families when they "came out" to reveal their sexual orientation.[17] Minority stress refers to the psychological trauma associated with widespread societal prejudice, e.g. against sexual minorities.[18] Some Brazilian studies have evaluated minority stress. One study showed that minority stress predicted depressive symptomatology among sexual minority men[19] while another study demonstrated that the odds ratio for suicide attempts more than doubled among young Brazilians experiencing sexual stigma.[20]

One mental health consequence of minority stress manifests in the form of eating disorders. Previous studies have demonstrated a higher prevalence of these disorders among sexual and gender minorities. $[21,22]$ Experiences of discrimination were associated with eating disorders and body image disturbance in all groups of women (homosexual, heterosexual and bisexual).[23]

In the present study we sought to examine the association between heteronormativity (as proxied by the prevalence of LGB youth in schools) and unhealthy weight-control behaviors among sexual minority youth.

\section{Methods}

The current study was a cross-sectional in Olinda in the state of Pernambuco, Brazil. Olinda had a population of 390,000 residents and 33 state public high schools in 2018.

The data were collected from February to June 2018 in $87 \%(n=27)$ of all state public high schools with daytime classes (31 schools), which agreed to take part in the study. The two schools offering only night classes were not invited. The response rate of all invited students enrolled in the 27 schools was $37.2 \%$ $(2,700)$. Almost all the classrooms $(91 \%)$ in the involved schools participated in our data collection.

The Informed Consent Form (ICF) was signed by the parents/guardians of all participants under 18-yearold while children also provided written assent. Participants over 18-years of age consented by themselves. This research was approved by the Ethics Committee of the University of Pernambuco ( $\mathrm{N}$. 2.361.780).

Four trained and calibrated examiners measured body weight and height with strong inter-rater reliability for height (kappa 0.99). A portable stadiometer (Sanny $\left.{ }^{\circledR}\right)$ and a self-zeroing digital scale (CAMRY) with a maximum capacity of $150 \mathrm{~kg}$ were used to measure height and body weight, respectively. The participants were weighed barefoot wearing socks and light clothing. 
The sociodemographic and health behavior modules were adapted from the U.S. Youth Risk Behavior Survey (YRBS) questionnaire.[24] The student's sociodemographic situation was assessed by their age, sex, and whether they received a family allowance. The family allowance is given in Brazil to poor families and extremely poor families with per-capita monthly incomes below \$170 BRL ( \$45 USD) or \$85 BRL ( \$23 USD), respectively.

The survey also asked whether the students had experienced victimization, whether they were actively trying to lose weight, as well as self-perception of happiness (In general, how do you feel in your actual life?) on a 5-point Likert scale.

Victimization was based on at least one positive answer for these three questions: (1. During the past 12 months, have you ever been bullied on school property?; 2. During the past 12 months, have you ever been electronically bullied? (Count being bullied through texting, Instagram, Facebook, WhatsApp or other social media.); 3. During the past 12 months, how many times has someone threatened or injured you with a weapon such as a gun, knife, or club on school property?). Trying to lose weight was based in the question "Which of the following are you trying to do about your weight?", with responses categorized as: trying to gain weight, stay the same weight or I am not trying to do anything about my weight, and trying to lose weight. Weight categories were based on cut-off $\mathrm{z}$ scores recommended by the WHO: underweight $(<-2)$, normal weight $(\geq-2$ and $<+1)$, overweight $(\geq+1$ and $<+2)$, obese $(\geq+2)$.[25]

The LGB variable was derived from adolescents who reported having sexual intercourse with a partner of the same sex or with partners of both sexes.

Our contextual variable of interest was LGB visibility in school, defined by the prevalence of LGB students in each school. The variable was dichotomized into low LGB visibility $(\leq 3.01 \%)$ vs. high LGB visibility $(>3.01 \%)$, where the cutoff was made at the 25 th percentile.

The outcome variable was unhealthy weight-control behaviors created by combining the following three behaviors: fasting, purging, and using diet pills.

Data analysis was carried out using STATA/IC version 15.1. We performed a sequence of multilevel logistic regressions (with random intercept) for the outcome of unhealthy weight-control behaviors (fasting, purging, or using diet pills). The empty model included only the dependent variable (Model 1). The second model included only the contextual variable (Model 2) and the third model included only individual variables. In the final model, we combined the individual and contextual variables (Model 4). We tested for potential mediation of the association between LGB visibility and unhealthy weight control behaviors by experiences of victimization and self-perception of happiness (models $4 \mathrm{a}$ and $4 \mathrm{~b}$ ). The cross-level interaction between the contextual variable (LGB visibility) and the individual variables (LGB and gender) were also tested. Some individual variables such as obesity, trying to lose weight, victimization, and self-perception of unhappiness were controlled for attenuates the association between LGB \& unhealthy weight-control behaviors. 
We used the proportional change in variance (PCV) to assess changes in the random intercept term. In other words, the PCV represents the proportional change in the area level variance compared to the empty model (Model 1).[26] We also used the Median Odds Ratio (MOR) to quantify the variation between clusters in each sequence of models.[27] When the MOR equals 1.0, it means that there is no heterogeneity between the contexts analyzed. We also tested the fitted multilevel logistic regression model using the Deviance (2 Res log-likelihood).

\section{Results}

A total of 2,500 students filled the questionnaires out of the 2,700 adolescents (and parents) who consented to participate in this study ( $92.6 \%$ rate response). The reasons for missing data in the survey were adolescents who did not allow anthropometric measurements $(n=53)$ or did not answer all questionnaire (the number is specific for each variable). More participants were female (55.9\%), older young $(74.7 \%)$, and non-receiving a family allowance (54.5\%) (Table 1$)$.

\section{Table 1 Sample characteristics}




\begin{tabular}{|c|c|}
\hline Variables & $\mathrm{N}(\%)$ \\
\hline Age & (N 2482) \\
\hline $14-15 y r s$ & 628 (25.3) \\
\hline $16-19$ yrs & $1854(74.7)$ \\
\hline Gender & (N 2438) \\
\hline Male & $1076(44.1)$ \\
\hline Female & $1362(55.9)$ \\
\hline Family allowance & (N 2421) \\
\hline No & $1320(54.5)$ \\
\hline Yes & $1101(45.5)$ \\
\hline LGB & (N 1194) \\
\hline No & $1066(89.3)$ \\
\hline Yes & $128(10.7)$ \\
\hline Victimization & (N 2498) \\
\hline No & $1870(74.9)$ \\
\hline Yes & $628(25.1)$ \\
\hline Self-perception of happiness & (N 2465) \\
\hline Fully happy/very happy/happy & $2034(82.5)$ \\
\hline Fully unhappy/not happy & $431(17.5)$ \\
\hline Trying to lose weight & (N 2447) \\
\hline No (gain weight, stay the same weight, or doing anything about weight) & $1558(63.7)$ \\
\hline Yes (lose weight) & $889(36.3)$ \\
\hline Obese & (N 2013) \\
\hline No & $1774(88.1)$ \\
\hline Yes & $239(11.9)$ \\
\hline Fasting & (N 2423) \\
\hline No & $2097(86.6)$ \\
\hline Yes & $326(13.5)$ \\
\hline Using diet pills & (N 2424) \\
\hline No & $2295(94.7)$ \\
\hline Yes & $129(5.3)$ \\
\hline Purging & (N 2412) \\
\hline No & $2315(96.0)$ \\
\hline Yes & $97(4.0)$ \\
\hline $\begin{array}{l}\text { Unhealthy weight-control } \\
\text { (fasting, using diet pills or purging) }\end{array}$ & (N 2385) \\
\hline No & 1957 (82.0) \\
\hline Yes & $428(18.0)$ \\
\hline
\end{tabular}

At the individual level, we found associations in the expected directions, such as higher reports of unhealthy weight control behaviors among LGB youth (OR: 1.9, 95\%Cl, 1.1-3.2) as well as adolescents reporting victimization (OR: $1.6,95 \% \mathrm{Cl}, 1.1-2.4)$. Over and above these individual associations, the contextual environment of low LGB visibility was also significantly associated with unhealthy weightcontrol behaviors (OR: 1.5, 95\% Cl, 1.0-2.2) (Table 2). However, when we tested cross-level interactions between school context and individual characteristics, they were not statistically significant: LGB visibility x LGB status (OR: $1.2,95 \% \mathrm{Cl}, 0.3-4.8$ ), LGB visibility $x$ gender (OR: $1.2,95 \% \mathrm{Cl}, 0.6-2.7$ ), or LGB visibility $x$ LGB adolescent $x$ gender (OR: $0.0,95 \% \mathrm{Cl}, 0.0-1.0$ ). In other words, low LGB visibility in schools was associated with higher odds of unhealthy weight control behaviors among both LBG and heterosexual youth.

Table 2 Multilevel adjustment for LGB visibility and unhealthy weight-control (fasting, using diet pills or purging) 


\begin{tabular}{|c|c|c|c|c|c|}
\hline Parameters & $\begin{array}{l}\text { Empty } \\
\text { model } \\
\text { (Model } \\
1)\end{array}$ & $\begin{array}{l}\text { Random } \\
\text { intercept, } \\
\text { fixed effects } \\
\text { contextual } \\
\text { variable } \\
\text { (Model 2) }\end{array}$ & $\begin{array}{l}\text { Random } \\
\text { intercept, } \\
\text { fixed effects } \\
\text { individual } \\
\text { variable } \\
\text { (Model 3) }\end{array}$ & $\begin{array}{l}\text { Random } \\
\text { intercept, fixed } \\
\text { effects (individual } \\
+\quad \text { contextual } \\
\text { variables) } \\
(\text { Model 4a) }\end{array}$ & \begin{tabular}{lr}
\multicolumn{2}{l}{ Random intercept, } \\
fixed effects \\
(individual \\
contextual \\
variables) \\
(Model 4b) \\
\end{tabular} \\
\hline \multicolumn{6}{|l|}{ Fixed part } \\
\hline \multicolumn{6}{|l|}{ Individual factors } \\
\hline$\overline{\text { Constant }}$ & $\begin{array}{l}0.2^{* * *} \\
{[0.2,0.3]}\end{array}$ & $\begin{array}{l}0.2 * * * \\
{[0.2,0.3]}\end{array}$ & $\begin{array}{l}0.0^{* * *} \\
{[0.0,0.1]}\end{array}$ & $\begin{array}{l}0.1 * * * \\
{[0.0,0.1]}\end{array}$ & $\begin{array}{l}0.0^{* * *} \\
{[0.0,0.1]}\end{array}$ \\
\hline $\begin{array}{l}\text { Age } \\
(16-19 \text { vs. } 14-15)\end{array}$ & & & $\begin{array}{l}1.8 \\
{[1.0,3.4]}\end{array}$ & $\begin{array}{l}1.6 \\
{[0.9,2.8]}\end{array}$ & $\begin{array}{l}1.8 \\
{[1.0,3.4]}\end{array}$ \\
\hline $\begin{array}{l}\text { Gender } \\
\text { (female vs. male) }\end{array}$ & & & $\begin{array}{l}1.7 * * \\
{[1.2,2.4]}\end{array}$ & $\begin{array}{l}1.7^{* *} \\
{[1.2,2.4]}\end{array}$ & $\begin{array}{l}1.7 * * \\
{[1.2,2.5]}\end{array}$ \\
\hline $\begin{array}{l}\text { Family allowance } \\
\text { (yes vs. no) }\end{array}$ & & & $\begin{array}{l}1.2 \\
{[0.8,1.7]}\end{array}$ & $\begin{array}{l}1.2 \\
{[0.8,1.7]}\end{array}$ & $\begin{array}{l}1.2 \\
{[0.8,1.7]}\end{array}$ \\
\hline LGB (yes vs. no) & & & $\begin{array}{l}1.7^{*} \\
{[1.0,2.9]}\end{array}$ & $\begin{array}{l}2.2 * * \\
{[1.3,3.7]}\end{array}$ & $\begin{array}{l}1.9 * \\
{[1.1,3.2]}\end{array}$ \\
\hline $\begin{array}{ll}\begin{array}{l}\text { Obese } \\
\text { (yes }\end{array} & \text { vs } \\
\text { normal/underweight) }\end{array}$ & & & $\begin{array}{l}2.1^{* *} \\
{[1.2,3.5]}\end{array}$ & $\begin{array}{l}2.1 * * \\
{[1.3,3.5]}\end{array}$ & $\begin{array}{l}2.1 * * \\
{[1.2,3.5]}\end{array}$ \\
\hline $\begin{array}{l}\text { Trying to lose weight (yes } \\
\text { vs. no) }\end{array}$ & & & $\begin{array}{l}2.4^{* * *} \\
{[1.6,3.7]}\end{array}$ & $\begin{array}{l}2.3 * * * \\
{[1.5,3.5]}\end{array}$ & $\begin{array}{l}2.4^{* * *} \\
{[1.6,3.7]}\end{array}$ \\
\hline $\begin{array}{l}\text { Victimization } \\
\text { (yes vs. no) }\end{array}$ & & & $\begin{array}{l}1.6^{*} \\
{[1.1,2.4]}\end{array}$ & & $\begin{array}{ll}1.6^{*} \\
{[1.1,2.4]}\end{array}$ \\
\hline $\begin{array}{lr}\text { Self-perception } & \text { of } \\
\text { unhappiness } & \text { (Fully } \\
\text { unhappy/not happy vs Fully } \\
\text { happy/very happy/happy) }\end{array}$ & & & $\begin{array}{l}1.8^{* *} \\
{[1.2,2.8]}\end{array}$ & & $\begin{array}{l}1.8^{*} \\
{[1.1,2.7]}\end{array}$ \\
\hline \multicolumn{6}{|l|}{$\begin{array}{l}\text { Contextual factors } \\
\text { (School level) }\end{array}$} \\
\hline LGB visibility (low vs. high) & & $\begin{array}{l}1.0 \\
{[0.8,1.4]}\end{array}$ & & $\begin{array}{l}1.5^{*} \\
{[1.0,2.2]}\end{array}$ & $\begin{array}{l}1.5^{*} \\
{[1.0,2.2]}\end{array}$ \\
\hline \multicolumn{6}{|l|}{ Random part } \\
\hline $\begin{array}{l}\text { Area level variance } \\
\text { (Random intercept) }\end{array}$ & $\begin{array}{l}0.2 \\
{[0.1,0.4]}\end{array}$ & $\begin{array}{l}0.2 \\
{[0.1,0.4]}\end{array}$ & $\begin{array}{l}0.2 \\
{[0.0,2.1]}\end{array}$ & $\begin{array}{l}3.37 \mathrm{e}-08 \\
{[0, .]}\end{array}$ & $\begin{array}{l}7.2 \mathrm{e}-1 \\
{[0, .]} \\
\end{array}$ \\
\hline$\overline{P C V \&}$ & & $-0 \%$ & $-26.0 \%$ & $-99.9 \%$ & $-99.9 \%$ \\
\hline Median Odds Ratio & $\begin{array}{l}\mathrm{MOR}= \\
1.3\end{array}$ & $\mathrm{MOR}=1.3$ & $\mathrm{MOR}=1.2$ & $\mathrm{MOR}=1.0$ & $\mathrm{MOR}=1.0$ \\
\hline 2 Res log-likelihood & 2238.1 & 2238.1 & $755.8^{* * *}$ & $783.3^{* * *}$ & $751.9^{* * *}$ \\
\hline Observations & 2385 & 2385 & 883 & 897 & 883 \\
\hline
\end{tabular}

$* \mathrm{p}<0.05, * * \mathrm{p}<0.01, * * * \mathrm{p}<0.001$

Comparing models $4 \mathrm{a}$ and $4 \mathrm{~b}$, we found some suggestion that the association between school LGB visibility and unhealthy weight control behaviors among LGB youth was mediated by experiences of victimization and self-perceptions of happiness.

\section{Discussion}

Our findings did not support our initial hypothesis that we would find higher unhealthy weight-control behaviors among LGB youth attending public schools with low LGB visibility. Instead, we found that schools with higher LGB visibility protect all students regardless of their sexual orientation. 
At the individual level, LGB youth were significantly more likely to report unhealthy weight-control behaviors in line with Lucassen et al.[28] Our findings also showed that at the individual level, there was some mediation of that association among LGB youth by personal experiences of bullying victimization and perceived low happiness. Our findings are consistent with previous studies $[23,29]$ showing that minority stress is associated with unhealthy weight control behaviors in sexual minority youth. Regarding the interaction between LGB $x$ gender at individual level, LGB boys were not significantly more likely to engage in unhealthy weight-control, although the direction of association was in the expected direction, in line with Hadland et al.[30]

However, the bigger picture from our study is that low LGB visibility is correlated with unhealthy weightcontrol behaviors in all students. One reason for this is because heteronormal schools are more likely to transmit "toxic" gender norms for both heterosexual youth and LGB youth. For heterosexual youth, these schools lead to unhealthy weight control behavior because boys \& girls are pressured to conform to distorted ideal body types popularized by marketing \& media, i.e. girls are expected to be thin \& boys are expected to be trim. For LGB youth, the same schools are unhealthy because of bullying and minority stress. In other words, these schools are "lose-lose" for everyone.

Our findings suggests the need for addressing LGB prejudice in the Brazilians school context.[31] One of the first steps for creating a safe and supportive school climate is to reinstate sexual education in the curriculum.[32] Other examples of actions that improve school climate include presentation of LGB films, [33] presence in the school of Gay-Straight Alliance for three or more years[34] and training for school staff to support LGB students.[4] According to Gower et al.[4] 4-6 practices had a much higher effect on victimization than 0-4 practices for an LGB supportive climate.

A limitation of our study is that the survey did not explicitly inquire about bullying specifically based on sexual orientation. Nor did we assess aspects of minority stress related to sexual orientation such as negative internalized stigma, discrimination related to sexual orientation, and acceptance by the family. In addition, our results may not be externally generalizable to other regions \& areas in Brazil. Finally, we did not directly assess LGB-supportive climate in the schools; instead we used a proxy for LGB visibility evaluated by the prevalence of LGB students in schools.

\section{Conclusion}

Our findings showed that low LGB visibility in schools is associated with unhealthy weight-control behaviors regardless of sexual orientation. So, our findings suggest that the Brazilian school scenario needs to combat the low LGB visibility in order to promote healthy development for all students, especially regarding mental health.

\section{Abbreviations}

LGB: Lesbian, Gay, and Bisexual youth 


\section{Declarations}

\section{Ethics approval and consent to participate}

All study procedures were approved before start by the Ethics Committee of University of Pernambuco ( $\mathrm{N}$. 2.361.780). All participants under 18-year-old provided written assent while written consent was obtained from their parents/guardians. Youth over 18 years old consented by themselves through a signing of the Inform Consent Form.

\section{Consent to publish}

Not applicable

\section{Availability of data and materials}

The datasets used and analyzed during the current study are available from the corresponding author on reasonable request.

\section{Competing interests}

The authors declare that they have no competing interests.

\section{Funding}

The authors declare that they received no financial support for this research.

\section{Authors' contributions}

CFBFS, FG, VAM, VC were responsible for the conception and design, and acquisition of data. CBFBFS and IK were responsible for data analysis interpretation and drafting of the manuscript. RCF, PMPAZ, IK were responsible for revising it critically for valuable intellectual content. All authors read and approved the final manuscript.

\section{Acknowledgements}

The authors wish to thank all the high school students who participated in this study.

\section{References}

1. Rose, I.D., et al., Sex Differences in School Safety and Bullying Experiences Among Sexual Minority Youth. J Sch Nurs, 2018. 34(4): p. 301-309.

2. Mooij, T., School Indicators of Violence Experienced and Feeling Unsafe of Dutch LGB Versus NonLGB Secondary Students and Staff, 2006-2010. J Interpers Violence, 2016. 31(20): p. 3413-3442. 
3. Smith, D.S., et al., Gender Norm Salience Across Middle Schools: Contextual Variations in Associations Between Gender Typicality and Socioemotional Distress. J Youth Adolesc, 2018. 47(5): p. 947-960.

4. Gower, A.L., et al., School Practices to Foster LGBT-Supportive Climate: Associations with Adolescent Bullying Involvement. Prev Sci, 2018. 19(6): p. 813-821.

5. Poteat, V.P., et al., The effects of general and homophobic victimization on adolescents' psychosocial and educational concerns: the importance of intersecting identities and parent support. J Couns Psychol, 2011. 58(4): p. 597-609.

6. Asinelli-Luz, A. and J.M.d. Cunha, Perceptions about the homophobic discrimination among high school graduates in Brazil from 2004 to 2008. Educar em Revista, 2011(39): p. 87-102.

7. Johns, M.M., et al., Strengthening Our Schools to Promote Resilience and Health Among LGBTQ Youth: Emerging Evidence and Research Priorities from The State of LGBTQ Youth Health and Wellbeing Symposium. LGBT Health, 2019. 6(4): p. 146-155.

8. Encarnación, O.G. A Latin American Puzzle: Gay Rights Landscapes in Argentina and Brazil. Human Rights Quarterly, 2018. 40, 194-218.

9. GGB and G.G.d. Bahia. Relatório parcial por ocasião do Dia Internacional Contra a Homofobia. Mortes de LGBT+ do Brasil (janeiro a 15 maio de 2019) Quem a homofobia matou hoje 2019; Available from: https://homofobiamata.files.wordpress.com/2019/05/relatc3b3rio-ggb-parcial2019.pdf.

10. Benevides, B.G. and S.N.B. Nogueira Dossiê: Assassinatos e violência contra travestis e transexuais no Brasil em 2018. 2019.

11. Irineu, B.A., 10 years of Brasil without homophobia program: critical notes. Temporais, 2014(28): p. 193-220.

12. Vivanco, J.M. A Voice for LGBT Rights Silenced in Brazil: Congressman Wyllys Quits Over Fears for His Life. 2019; Available from: https://www.hrw.org/news/2019/01/24/voice-lgbt-rights-silencedbrazil.

13. Faiola, A. and M. Lopes. The Americas: LGBT rights threatened in Brazil under new far-right president. 2019; Available from: https://www.washingtonpost.com/world/the_americas/lgbt-rightsunder-attack-in-brazil-under-new-far-right-president/2019/02/17/b24e1dcc-1b28-11e9-b8e6567190c2fd08_story.html.

14. AFP. Brazilian president says decision to criminalise homophobia 'completely wrong'. 2019; Available from: https://www.euronews.com/2019/06/15/brazilian-president-says-decision-to-criminalisehomophobia-completely-wrong.

15. Barbosa, L.U.a., C.t.S.C.L. Viçosa, and V. Folmer, Sex education in the education policy documents and their significance. Revista Eletrônica Acervo Saúde / Electronic Journal Collection Health, 2019. 11(10).

16. Brasil. Senado Federal. Tornar crime o ensino de ideologia de gênero nas escolas brasileiras. 11/jul/2019; Available from: 
https://www25.senado.leg.br/web/atividade/materias/-/materia/133917.

17. Braga, I.F., et al., Family violence against gay and lesbian adolescents and young people: a qualitative study. Rev. Bras. Enferm., 2018. 71: p. 1220-1227.

18. Meyer, I.H., Prejudice, social stress, and mental health in lesbian, gay, and bisexual populations: conceptual issues and research evidence. Psychol Bull, 2003. 129(5): p. 674-697.

19. Dunn, T.L., et al., Does the minority stress model generalize to a non-U.S. sample? An examination of minority stress and resilience on depressive symptomatology among sexual minority men in two urban areas of Brazil. Psychology of Sexual Orientation and Gender Diversity, 2014. 1(2): p. 117-131.

20. Brandelli Costa, A., et al., The Experience of Sexual Stigma and the Increased Risk of Attempted Suicide in Young Brazilian People from Low Socioeconomic Group. Front Psychol, 2017. 8: p. 192.

21. Calzo, J.P., et al., Eating Disorders and Disordered Weight and Shape Control Behaviors in Sexual Minority Populations. Curr Psychiatry Rep, 2017. 19(8): p. 49.

22. Watson, R.J., et al., Trends and disparities in disordered eating among heterosexual and sexual minority adolescents. Int J Eat Disord, 2017. 50(1): p. 22-31.

23. Henn, A.T., et al., Body Image as Well as Eating Disorder and Body Dysmorphic Disorder Symptoms in Heterosexual, Homosexual, and Bisexual Women. Front Psychiatry, 2019. 10: p. 531.

24. Guedes, D.P. and C.C. Lopes, Validation of the Brazilian version of the 2007 Youth Risk Behavior Survey. Rev Saude Publica, 2010. 44(5): p. 840-50.

25. de Onis, M., et al., Development of a WHO growth reference for school-aged children and adolescents. Bull World Health Organ, 2007. 85(9): p. 660-7.

26. Merlo, J., et al., A brief conceptual tutorial on multilevel analysis in social epidemiology: investigating contextual phenomena in different groups of people. J Epidemiol Community Health, 2005. 59(9): p. 729-36.

27. Larsen, K. and J. Merlo, Appropriate assessment of neighborhood effects on individual health: integrating random and fixed effects in multilevel logistic regression. Am J Epidemiol, 2005. 161(1): p. 81-8.

28. Lucassen, M.F., et al., Body size and weight, and the nutrition and activity behaviours of sexual and gender minority youth: findings and implications from New Zealand. Public Health Nutr, 2019. 22(13): p. 2346-2356.

29. Himmelstein, M.S., R.M. Puhl, and R.J. Watson, Weight-based victimization, eating behaviors, and weight-related health in Sexual and Gender Minority Adolescents. Appetite, 2019. 141: p. 104321.

30. Hadland, S.E., et al., Weight misperception and unhealthy weight control behaviors among sexual minorities in the general adolescent population. J Adolesc Health, 2014. 54(3): p. 296-303.

31. González-Jiménez, A.J. and V. Fischer, Gender and Sexual Orientation among Adolescents in Brazil: An Analysis of the Prejudice and Bullying in the Educational Context. Procedia - Social and Behavioral Sciences, 2017. 237: p. 38-43. 
32. Proulx, C.N., et al., Associations of Lesbian, Gay, Bisexual, Transgender, and Questioning-Inclusive Sex Education With Mental Health Outcomes and School-Based Victimization in U.S. High School Students. J Adolesc Health, 2019. 64(5): p. 608-614.

33. Burk, J., M. Park, and E.M. Saewyc, A Media-Based School Intervention to Reduce Sexual Orientation Prejudice and Its Relationship to Discrimination, Bullying, and the Mental Health of Lesbian, Gay, and Bisexual Adolescents in Western Canada: A Population-Based Evaluation. Int J Environ Res Public Health, 2018. 15(11).

34. Saewyc, E.M., et al., School-Based Strategies to Reduce Suicidal Ideation, Suicide Attempts, and Discrimination among Sexual Minority and Heterosexual Adolescents in Western Canada. Int J Child Youth Family Stud, 2014. 5(1): p. 89-112.

\section{Supplementary Files}

This is a list of supplementary files associated with this preprint. Click to download.

- STROBEchecklistBMC.doc 